\title{
Money Attitudes in Monetary and Non-Monetary Criminals in China
}

\author{
Yuxuan Chen ${ }^{1}$

\begin{abstract}
${ }^{1}$ Department of Psychology, University of California at Berkeley, Berkeley, CA 94720, United States yuxuan.chen@berkeley.edu
\end{abstract}

\begin{abstract}
The current investigation examined the difference in money attitudes between inmates who committed monetary crimes and those who committed non-monetary crimes. Monetary inmates $(N=219)$ and non-monetary inmates $(N=174)$ responded to a questionnaire that included the Money Attitude Scale (MAS). Results indicated that monetary criminals scored higher in Power-Prestige and Anxiety dimensions and lower in Retention-Time dimension than non-monetary inmates. The two groups did not show a significant difference in their scores in Distrust dimension. Our discussion focuses on the implications of these results for current studies and educational programs regarding the money attitudes of inmates.
\end{abstract}

Keywords: Money Attitudes, Inmates, Monetary Crimes, Chinese

\section{INTRODUCTION}

Money is an important factor in studying human behaviour. Extensive research has proven money to be a substantial motivation for human behaviour across cultures [1] [2] [3] [4] [5]. While money can be an incentive for productivity, it can also motivate unethical behaviour. Statistics have shown that in 2018, there were $7,478,106$ offenses of robbery, burglary, and theft in the United States, surpassing the number of all other offenses combined: 155,594 cases [6]. In China, there were $3,979,037$ cases of robbery, theft, fraud, or counterfeit filed at public security offices, compared to 1,090,205 non-monetary and uncategorised offenses [7]. The overwhelming number of monetary offenses suggests that preventing and controlling monetary crime would significantly help construct a safer society. In order to understand the motivation behind these monetary crimes, it is crucial to understand the offenders' attitudes regarding finance. Past research has demonstrated that moderating money attitudes can contribute towards stronger ethical attitudes [8]. Additionally, Schram and Morash (2002) evaluated a life-skill training program implemented by the Michigan Department of Corrections in several women's prisons [9]. They concluded that through learning and practicing skills such as money management, incarcerated women cultivated more sustainable financial attitudes that decrease potential criminality following their release from prison. This suggested that implementing educational programs to promote positive money attitudes in prison and other institutions in the community is a promising approach to reduce monetary crime in the society. Through studying inmates' monetary attitudes, researchers facilitate the design and implementation of such interventions.

Many psychologists from different cultures have used Yamauchi and Templer's (1982) Money Attitude Scale (MAS) to assess individuals' perspectives regarding money and personal finance [10] [11] [12] [13] [14] [15]. The MAS consists of four subscales as follows. (1) Power-Prestige measures the extent to which an individual views money as a symbol of success and uses money to influence others. (2) Distrust measures an individual's trust in situations involving money. (3) Anxiety measures the extent to which money affects an individual's anxiety level. (4) Retention-Time measures an individual's financial organisation skills, such as budgeting.

Previous scholarly work has drawn a connection between money attitudes and unethical intentions and behaviour. Tang \& Chiu (2003) found that individuals who regarded money as a symbol of success and power were more likely to engage in unethical behaviour in organisational settings, such as abusing power or resources [15]. Similarly, extended research has demonstrated that such a perspective regarding money was positively correlated with unethical intentions and behaviour, and tolerance of ethically questionable behaviour [16] [17] [18] [19] [20]. Empirical studies also suggested that people who were more conscientious in 
managing their finances were less accepting of unethical scenarios [8]. Guided by previous work that examined money attitudes in school and industrial organisation contexts, we extended money attitude research to include prisoners. Specifically, we separated monetary crimes from other types of crimes, as monetary crime is a substantial category of offense that possibly stem from different psychological motivations regarding money attitudes.

In the present research, we investigated whether the monetary attitude of inmates who committed monetary crimes differs from that of non-monetary inmates, as individual characteristics and antisocial behaviour may vary across categories of offense [21]. Building upon previous findings, we posited that monetary inmates score higher in Power-Prestige dimension and lower in Retention-Time dimension in MAS than non-monetary inmates (Hypothesis 1 and 2). The exploratory goal of the present investigation was to assess whether the two groups differ in the Distrust and Anxiety dimensions of the MAS.

\section{METHOD}

\subsection{Participants}

The full sample consisted of 400 male inmates from a prison in Shandong, China. The prison staff administered the questionnaire in November 2019. All administrative personnel and participants are fluent in Chinese. Participants were informed about the nature of the survey and asked for consent. They were allowed to withdraw from the survey or skip any question at any time without explanation or prejudice. Inmates who provided consent completed the survey on paper.

7 participants who did not specify crime type were excluded from analysis, leaving a total $N$ of 393. All participants are male and of Chinese ethnicity. Of the participants, $219(55.73 \%)$ committed monetary crime, and $174(44.27 \%)$ committed non-monetary crime. Participants ranged in age from 18 to 58 years old, with an average age of 34.85 years old $(S D=8.19)$. Mean ages were $34.67(S D=8.32)$ years old for monetary criminals and $35.08(S D=8.06)$ years old for non-monetary criminals.

\subsection{Material}

We used Yamauchi and Templer's (1982) Money Attitude Scale (MAS) to measure participants' attitudes towards money [10]. The questionnaire consists of 29 items of four theoretical dimensions: Power-Prestige (9 items), Distrust (7 items), Anxiety (6 items), and Retention-Time (7 items). Participants responded to each item on a Likert scale ranging from 1 to $5(1=$ Strongly Disagree to $5=$ Strongly Agree). In order to evaluate the internal consistency of each domain, we calculated Cronbach's alpha coefficients for each dimension. The Cronbach's alpha value varies from 0 to 1 , and a value of 0.60 or above indicates satisfactory internal consistency [22]. The Cronbach's alpha coefficients of each domain ranged from $\alpha=0.76$ (Anxiety) to $\alpha=0.86$ (RetentionTime) for monetary criminals, and from $\alpha=0.70$ (Anxiety) to $\alpha=0.87$ (Retention-Time) for non-monetary criminals, resembling results from previous studies [10] [13] [23] [24].

After completing the questionnaire, participants answered a series of demographic questions. All survey materials were translated into and administered in Chinese. In order to ensure functional equivalence between the source and target versions of the survey, we adapted the back-translation techniques that are commonly used in cross-cultural research [25]. All materials were translated into Chinese by a researcher fluent in both English and Chinese. The Chinese translation was subsequently translated back into English by a different bilingual researcher. The translators compared the original English survey with the backtranslation and made final edits to the Chinese version.

\section{RESULTS}

\subsection{Confirmatory factor analysis}

In order to test whether the factor structures of the MAS are different between monetary and non-monetary inmates, we conducted a multi-group confirmatory factor analysis [26]. Our model hypothesised that the factor structures of monetary and non-monetary inmates were statistically different, $\chi^{2}(371)=970.519, p<.001, \mathrm{CFI}$ $=.825, \mathrm{RMSEA}=.070,90 \% \mathrm{CI}=[.065-.075]$. Because our p-value was less than .05, RMSEA was less than .08, and CFI was close to .90 , we concluded that monetary and non-monetary inmates showed statistically equivalent factor structures of the MAS. These results indicated that the MAS is an appropriate measure of money attitudes among monetary and non-monetary inmates.

\subsection{Correlations and differences of correlations between the groups}

We calculated the correlation coefficients among the MAS dimensions and examined the differences of the coefficients between the two groups of inmates (see Table 1). Almost all correlation coefficients were statistically equal between the groups, except for the correlations between Distrust and Power-Prestige, and Distrust and Anxiety. These results demonstrated that monetary and non-monetary inmates showed statistically equivalent inter-dimensional relationships of the MAS. 
Table 1 Correlation coefficients among the four dimensions for monetary and non-monetary inmates.

\begin{tabular}{|c|c|c|c|c|c|}
\hline Dimension & & $\begin{array}{l}\text { Power } \\
\text { Prestige }\end{array}$ & Distrust & Anxiety & $\begin{array}{l}\text { Retention } \\
\text { Time }\end{array}$ \\
\hline \multirow[t]{3}{*}{ Power Prestige } & Monetary criminals & - & $0.484^{\star \star \star}$ & $0.624^{\star \star *}$ & $0.200^{\star *}$ \\
\hline & Non-monetary criminals & - & $0.392^{* \star *}$ & $0.637^{\star \star \star}$ & $0.191^{*}$ \\
\hline & $z$ & & 1.666. & -0.254 & 0.215 \\
\hline \multirow[t]{3}{*}{ Distrust } & Monetary criminals & & - & $0.642^{* * *}$ & $0.213^{\star *}$ \\
\hline & Non-monetary criminals & & - & $0.376^{\star * *}$ & $0.231^{* *}$ \\
\hline & $z$ & & & $4.790^{\star * \star}$ & -0.387 \\
\hline \multirow[t]{3}{*}{ Anxiety } & Monetary criminals & & & - & $0.251^{* * *}$ \\
\hline & Non-monetary criminals & & & - & $0.285^{* * *}$ \\
\hline & $z$ & & & & -0.709 \\
\hline \multirow[t]{2}{*}{ Retention Time } & Monetary criminals & & & & - \\
\hline & Non-monetary criminals & & & & - \\
\hline
\end{tabular}

Note. Monetary criminals ( $N=188$, because of missing values). Non-monetary criminals $(N=143$, because of missing values) $z=$ difference in correlation coefficients between the groups. $. \mathrm{p}<.1 . * \mathrm{p}<.05 . * * \mathrm{p}<.01 . * * * \mathrm{p}<.001$.

\subsection{Mean differences of MAS between two groups}

We performed a t-test between monetary and nonmonetary inmates, with MAS dimensions as the dependent variables (see Table 2 for results). Consistent with our hypotheses 1 and 2, we found that monetary inmates scored significantly higher in Power-Prestige dimension $(F(1,371)=4.373, p=0.0372)$ and significantly lower in Retention-Time dimension ( $\mathrm{F}$ (1, $371)=4.298, p=0.0388)$ compared to non-monetary inmates. Exploratory analyses revealed that monetary inmates scored moderately higher in Anxiety dimension $(\mathrm{F}(1,371)=3.159, p=0.0763)$ than non-monetary inmates. There was no significant difference between the two groups in their scores in Distrust dimension ( $\mathrm{F}$ (1, $371)=1.442, p=0.231)$.

Table 2 Mean scores of the four dimensions among monetary and non-monetary inmates.

\begin{tabular}{|c|c|c|c|c|c|c|}
\hline Dimension & & $M$ & $S D$ & $t$ & $S E$ & $F$ \\
\hline \multirow[t]{2}{*}{ Power Prestige } & Monetary criminals & 21.69 & 6.472 & \multirow{2}{*}{$2.091^{*}$} & \multirow{2}{*}{0.658} & \multirow{2}{*}{4.373} \\
\hline & Non-monetary criminals & 22.87 & 5.906 & & & \\
\hline \multirow[t]{2}{*}{ Distrust } & Monetary criminals & 16.35 & 5.403 & \multirow{2}{*}{1.201} & \multirow{2}{*}{0.543} & \multirow{2}{*}{1.442} \\
\hline & Non-monetary criminals & 17.08 & 4.988 & & & \\
\hline \multirow[t]{2}{*}{ Anxiety } & Monetary criminals & 15.94 & 4.613 & \multirow{2}{*}{1.777.} & \multirow{2}{*}{0.468} & \multirow{2}{*}{3.159} \\
\hline & Non-monetary criminals & 16.71 & 4.254 & & & \\
\hline \multirow[t]{2}{*}{ Retention Time } & Monetary criminals & 24.55 & 5.625 & \multirow{2}{*}{$-2.073^{*}$} & \multirow{2}{*}{0.589} & \multirow{2}{*}{4.298} \\
\hline & Non-monetary criminals & 23.50 & 5.501 & & & \\
\hline
\end{tabular}

Note. Monetary criminals ( $N=188$, because of missing values). Non-monetary criminals $(N=143$, because of missing values). $z=$ difference in correlation coefficients between the groups.

$. \mathrm{p}<.1 . * \mathrm{p}<.05 . * * \mathrm{p}<.01 . * * * \mathrm{p}<.001$. 


\section{CONCLUSION}

Although many previous studies have examined how money attitudes influence individuals' unethical intentions and behaviour in organisations [17] [18], limited work has explored how money attitudes vary among inmates who committed different types of offenses. The present investigation compared mean scores of the four dimensions of MAS among inmates who committed monetary crimes and those who committed non-monetary crimes. Overall, our study suggested significant differences in monetary attitudes between monetary and non-monetary inmates.

More specifically, in keeping with our first hypothesis, we found that monetary inmates held stronger beliefs in the power and influence of money compared to non-monetary inmates. This discovery was in accordance with previous findings that people who consider money as an indication of success are more likely to engage in unethical behaviour [15]. For these individuals, the power and status associated with wealth may be a strong incentive to forgo other moral values and beliefs. Thus, they are more likely to challenge social rules in order to build wealth even under risk of arrest.

In line with Hypothesis 2, we found that monetary inmates have poorer financial organisational skills than non-monetary inmates. This result echoed with Schram and Morash's (2002) conclusion that personal finance management training for inmates mitigates characteristics that can result in criminality [9]. It is possible that individuals with poorer budgeting skills and spending habits often struggle financially and thus would consider illegal ways to obtain money. Another plausible explanation is that irrational buying behaviour and criminal behaviour may both stem from impulsivity and a lack of self-control; in other words, individuals who tend to go on spending sprees might also be disposed to engage in offending behaviour. Future research on money attitudes should include general population samples to compare with incarcerated individuals who committed different types of offenses.

Exploratory analyses revealed that monetary inmates reported a higher level of money-related anxiety than non-monetary inmates. We presume that the anxiety regarding money motivates these individuals to obtain money for a sense of safety. When facing the fear of instability and uncertainty, individuals might choose to pursue financial security through illegal methods. Further investigation is needed to understand the mechanism behind money-related anxiety and offending behaviour.

Finally, possibly due to the small sample size, we did not observe a significant difference between the two groups in their ratings in the Distrust dimension. Taken as a whole, the aforementioned findings lend support to our central hypothesis that money attitudes differ between monetary and non-monetary criminals.

There are several limitations and future directions that merit attention. First of all, the sample size was relatively small and the subject population was not diverse. Additional work should include a larger participant pool with more participants of other ethnicities, which would account for other potential cultural variance. Moreover, prison experience varies among different countries and regions, which might influence inmates' attitudes toward money. Future investigation should assess the monetary attitudes of incarcerated women. Extensive research has suggested that females differed significantly from males in terms of their monetary attitudes, such that females experience greater negative emotions, including envy, in respect to money [27] [28], and are less likely to have unethical intentions or take moral risks for money [29] [30]. In addition, the present study did not control for the length of sentence of each prisoner and the length of confinement up to the point of the study, which could influence the inmates' money attitudes. Furthermore, the present study generalised all types of offenses into two categories, monetary and non-monetary, while the characteristics within each category of crime are diverse. For example, both robbery with violence and financial fraud were categorised as monetary crimes, and both homicide and intentional injury were categorised as nonmonetary crimes. Inmates who committed monetary crimes could significantly differ from each other in terms of their money attitudes. Future research should include more specific categorisation and examine the details of the crimes. Finally, the present study only included monetary and non-monetary inmates. Future studies should explore the difference between inmates and the general population in terms of their money attitudes.

\section{ACKNOWLEDGMENT}

This project was supported by Jinan Prison of Shandong Province.

\section{REFERENCES}

[1] Harpaz I. The Importance of Work Goals: An International Perspective[J]. Journal of International Business Studies, 1990, 21(1):75-93.

[2] Herzberg F. One more time: how do you motivate employees? 1968.[J]. Harvard business review, 2003, 81(1):87-96.

[3] Locke, E. A., Feren, D. B., McCaleb, V. M., Shaw, K. N., \& Denny, A. T. (1980). The relative effectiveness of four methods of motivating employee performance. Changes in working life, 363(1), 388.

[4] Srivastava A, Locke E A, Bartol K M. Money and subjective well-being: It's not the money, it's the 
motives. [J]. Journal of Personality \& Social Psychology, 2001, 80(6):959-971.

[5] Li-Ping Tang, Thomas, Tillery K R, Lazarevski B, et al. The love of money and work-related attitudes[J]. Journal of Managerial Psychology, 2004, 19(5): 542-548.

[6] Federal Bureau of Investigation Uniform Crime Reporting Program. (2018). Offense analysis in the United States (Data file). Retrieved from https://ucr.fbi.gov/crime-in-the-u.s/2018/crime-inthe-u.s.-2018/tables/table-7

[7] National Bureau of Statistics of China. (2018). National data of criminal cases filed at public security offices (Data file). Retrieved from http://data.stats.gov.cn/easyquery.htm?cn=C01\&zb $=\mathrm{A} 0 \mathrm{~S} 0 \mathrm{G} 02 \& \mathrm{sj}=2018$

[8] Wong H M. Religiousness, Love of Money, and Ethical Attitudes of Malaysian Evangelical Christians in Business[J]. Journal of Business Ethics, 2008, 81(1): p.169-191.

[9] Schram, P. J., \& Morash, M. (2002). Evaluation of a life skills program for women inmates in Michigan. Journal of Offender Rehabilitation, 34(4), 47-70.

[10] Yamauchi K T, Templer D J. The Development of a Money Attitude Scale[J]. Journal of Personality Assessment, 1982, 46(5):522-528.

[11] Lejoyeux, M., Richoux-Benhaim, C., Löhnardt, H., \& Lequen, V. (2011). Money attitude, self-esteem, and compulsive buying in a population of medical students. Frontiers in psychiatry, 2, 13.

[12] Lin, L. Y., \& Shih, H. Y. (2012). The relationship of university student's lifestyle, money attitude, personal value and their purchase decision. International journal of Research in Management, 1(2), 19-37.

[13] Medina J F , Saegert J , Gresham A . Comparison of Mexican-American and Anglo-American Attitudes Toward Money[J]. Journal of Consumer Affairs, 2005, 30(1):124-145.

[14] Roberts, J. A., \& Sepulveda M, C. J. (1999). Money attitudes and compulsive buying: an exploratory investigation of the emerging consumer culture in Mexico. Journal of International Consumer Marketing, 11(4), 53-74.

[15] Tang L P, Chiu R K. Income, Money Ethic, Pay Satisfaction, Commitment, and Unethical Behavior: Is the Love of Money the Root of Evil for Hong Kong Employees?[J]. Journal of Business Ethics, 2003, 46(1): p.13-30.

[16] Harmon, P. (2019). Business process change: a business process management guide for managers and process professionals. Morgan Kaufmann.

[17] Jones G E, Kavanagh M J. An Experimental Examination of the Effects of Individual and Situational Factors on Unethical Behavioral Intentions in the Workplace[J]. Journal of Business Ethics, 1996, 15(5):511-523.
[18] Tang L P, Liu H. Love of Money and Unethical Behavior Intention: Does an Authentic Supervisor's Personal Integrity and Character (ASPIRE) Make a Difference?[J]. Journal of Business Ethics, 2012, 107(3):295-312.

[19] Tang, T. L. P., Sutarso, T., Ansari, M. A., Lim, V. K., Teo, T. S., Arias-Galicia, F., ... \& Vlerick, P. (2018). Monetary Intelligence and Behavioral Economics: The Enron Effect-Love of money, corporate ethical values, Corruption Perceptions Index (CPI), and dishonesty across 31 geopolitical entities. Journal of Business Ethics, 148(4), 919937.

[20] Vitell S J , Singh J J , Paolillo J . Consumers' Ethical Beliefs: The Roles of Money, Religiosity and Attitude toward Business[J]. Journal of Business Ethics, 2007, 73(4):p.369-379.

[21] Burt S A. Are there meaningful etiological differences within antisocial behavior? Results of a meta-analysis $[\mathrm{J}]$. Clinical Psychology Review, 2009, 29(2):0-178.

[22] Malhotra N K , Kim S S , Agarwal J . Internet Users' Information Privacy Concerns (IUIPC): The Construct, the Scale, and a Causal Model[J]. Information Systems Research, 2004, 15(4): p.336355.

[23] Roberts, J. A., \& Sepulveda M, C. J. (1999). Money attitudes and compulsive buying: an exploratory investigation of the emerging consumer culture in Mexico. Journal of International Consumer Marketing, 11(4), 53-74

[24] Yang, B., \& Lester, D. (2002). Internal consistency of the Yamauchi/Templer money attitude scale. Psychological reports, 91(3), 994-994.

[25] Stewart V. Back-translation and other translation techniques in Cross-cultural research[J]. cmaj canadian medical association journal, 1990, 143(10):1017-1024.

[26] Vandenberg R J, Lance C E. A Review and Synthesis of the Measurement Invariance Literature: Suggestions, Practices, and Recommendations for Organizational Research[J]. Organizational Research Methods, 2000, 3(1):4-70.

[27] Christopher A N, Marek P, Carroll S M. Materialism and attitudes toward money: An exploratory investigation[J]. Individual Differences Research, 2004, 2(2):109-117.

[28] Prince M. Women, men and money styles[J]. Journal of Economic Psychology, 1993, 14(1):175182.

[29] Furnham, A. Your Money or Your Life: Behavioral and Emotional Predictors of Money Pathology[J]. Human Relations, 1999, 52(9):1157-1177.

[30] Tang L P, Sutarso T. Falling or Not Falling into Temptation? Multiple Faces of Temptation, Monetary Intelligence, and Unethical Intentions Across Gender[J]. Journal of Business Ethics, 2013, 116(3):529-552. 